Cad.Est.Ling., Campinas, (44):325-337, Jan./Jun. 2003

\title{
ESTRUTURAS INTERATIVAS EM AULAS VIRTUAIS UMA ANÁLISE ETNOGRÁFICA
}

\author{
KAZUE SAITO MONTEIRO DE BARROS \\ (Universidade Federal de Pernambuco)
}

\begin{abstract}
Discussions in pedagogical chats are often triggered by questions, proposed either by the teacher or the students. In pedagogical exchanges via e-mails, it is unusual to find discussions originated by questions. Rather, the questions are more often interpreted as requests for information by the teacher/tutor. This paper comments on this peculiar trend found in our data and examines why apparentely similar questions which appear in both genres - pedagogic chats and e-mails - result in differentiated typological sequences.
\end{abstract}

\section{INTRODUÇÃO}

\section{Tema e objetivos}

Este trabalho é motivado por uma curiosa constatação que fizemos ao compararmos duas formas de aulas virtuais, as aulas chat e aulas por e-mail ${ }^{1}$. As análises evidenciaram que, nas primeiras, há uma tendência marcante da ocorrência de estruturas argumentativas, o que é natural se considerado que, quase sempre, o tópico se desenvolve através de discussões. Comparativamente, nas aulas por e-mail parece ser mais freqüente o uso de sequiências tipológicas expositivas, sendo raras as discussões. Observamos que, assim como é comum ocorrer em aulas presenciais, também nas aulas chat muitas discussões são desencadeadas por perguntas ${ }^{2}$

${ }^{1}$ As aulas apresentam formas bastante variáveis. As aulas chat podem se constituir como unidades bastante complexas e longas. Os encontros podem ser abortados por dificuldades na interação, mas sempre apresentam aberturas e fechamentos característicos. Diferentemente, as aulas por e-mail são mais difíceis de delimitar. Em alguns casos, nem mesmo se tem convicção da existência de uma unidade "aula", pois os intercâmbios podem ser curtos e não apresentar aquela monitoração temática tão característica das aulas. Algumas vezes, vários intercâmbios podem formar unidades maiores que parecem corresponder ao que, no ensino à distância, é chamado de módulo. Com essas observações, queremos enfatizar que, pelo menos no momento, os resultados não são generalizáveis a outros casos, já que o termo "aula virtual" compreende interações complexas e de múltiplas facetas. As dificuldades na delimitação das aulas, no entanto, não chegam a comprometer os resultados da pesquisa, já que se trata de uma unidade de cunho pedagógico.

${ }^{2}$ Geralmente, as perguntas podem ser classificadas como injuntivas, seguindo uma posição adotada por Marcuschi (2002). Procurou-se evitar incluir discussões sobre outras visões teóricas (por exemplo, as de 
formuladas pelo professor ou pelo aluno. Verificamos também que, nas trocas por $e$ mail, as perguntas do aluno são tratadas como meros pedidos de informação. Assim, achamos pertinente examinar com mais cuidado o porquê da ausência de discussões em aulas por e-mail ou, sob outra perspectiva de observação, porque perguntas aparentemente semelhantes desencadeiam sequiências diferenciadas - este é o objetivo central do presente trabalho. Como será visto, são vários os fatores que colaboram para que isso ocorra. As observações aqui reunidas consideram aspectos não só da organização lingüística e conversacional, mas também sociointeracionais e etnográficos.

É cada vez mais aceita a distinção entre tipo textual e gênero textual, sendo o primeiro conceito definido a partir de suas propriedades lingüísticas e, o segundo, como unidade empiricamente atualizada em situações reais de comunicação. Reconhece-se, por um lado, que um gênero pode abrigar vários tipos. Mas também se admite, por outro, que há estruturas tipológicas características de alguns gêneros. Neste trabalho, considera-se que as duas formas de aulas analisadas, as aulas chat e as aulas via e-mail, constituem gêneros textuais distintos (esta questão será retomada mais adiante). Como dito, no contexto dos gêneros de aulas estudados, a discussão pedagógica e a solicitação de informações não parecem ocorrer de forma randômica. Dessa forma, o objetivo explicitado mais acima traduz-se, teoricamente, na seguinte questão: no âmbito das duas aulas virtuais em foco, pode-se falar de uma correlação efetiva entre gênero textual e tipo textual?

\section{Dados}

Pode-se considerar que há duas formas de acesso às redes, públicas ou privadas. Nas públicas, não há registro de usuários e qualquer pessoa pode acessar a qualquer momento; as privadas são restritas a grupos de assinantes, por exemplo, de uma mesma empresa ou universidade. Cada uma delas pode ainda ser aberta ou fechada. Quando aberta, todos os usuários do mesmo canal vêem o que é colocado na tela, mas há a alternativa de conversas fechadas, entre dois dos usuários (o chamado 1/1).

As aulas chat se constituem como encontros previamente combinados entre professores e alunos. Elas compartilham várias características com os chats casuais, muitas delas concretizadas pelas condições de formulação. A diferença se dá pelo fato do tópico ser pré-estabelecido e seu desenvolvimento monitorado. O canal utilizado pelo grupo de professores e alunos da nossa amostra é privado. Não há evidências de uso do sistema fechado em aulas chat, já que o bate papo reservado é visto como comportamento condenável. Em aulas, mesmo aqueles que não estão efetivamente interagindo, têm que participar da interação na qualidade de audiência. Para este trabalho, foram observadas oito aulas chat, mas análises anteriores permitem afirmar que os resultados se aplicam a um universo muito maior.

Bronckart, 1999 e Adam, 1990) a esse respeito e no tocante à teoria dos gêneros como um todo, por considerar que isso sobrecarregaria em demasiado o texto. 
A segunda forma de aula, por e-mail, tem um pouco mais de tradição. Os alunos compram um curso completo. Geralmente, não conhecem o professor ou os outros possíveis alunos que podem estar geograficamente bastante distantes. Lêem textos que lhes são disponibilizados e os discutem com o professor por meio de correio eletrônico. Nos dados que vamos analisar, a forma de acesso é privada e fechada, isto é, as trocas entre um aluno e o professor são personalizadas. Inclusive, pela observação de anúncios, pode-se inferir que a privacidade e o acompanhamento individualizado parecem ser os principais atrativos desse tipo de curso. As oito aulas por e-mail que servem de base para este estudo apresentam estrutura organizacional tripartida, envolvendo três momentos distintos: primeiro, o agendamento de uma tarefa por parte do professor (por exemplo, a leitura de um texto), segundo, o cumprimento desta tarefa pelo aluno e, terceiro, a troca de $e$-mails, por iniciativa do aluno. Vamos nos reportar a esta última fase, a seção de acompanhamento, limitando a análise à troca de mensagens por correio eletrônico entre professor e aluno.

Como os demais trabalhos que se inserem no âmbito do nosso projeto de pesquisa sobre a interação em aulas virtuais, esta investigação adota enfoque empírico e metodologia indutiva, neste aspecto, apoiando-se nos preceitos dos analistas da conversação. Com tendência à análise etnográfica, postula que as interpretações do analista devem ser filtradas pelo olhar do usuário, isto é, o analista deve considerar que o falante lança mão de dadas estratégias em função de suas expectativas e das formas pelas quais ele interpreta a atividade da qual participa. Assim, unindo tendências, a observação parte da identificação de padrões recorrentes para, então, buscar estabelecer relações entre as regularidades das formas e conteúdos da comunicação e as características externas à interação. A exposição que se segue reflete a metodologia do trabalho: primeiro, apresentamos os dados com as seqüências identificadas (item 2) para, depois, buscarmos as justificativas de sua ocorrência (item 3).

\section{DISCUSSÃo PEDAGÓGICA E SOLICITAÇÃO DE INFORMAÇÃO EM AULAS VIRTUAIS.}

\subsection{Discussão pedagógica na aula chat}

A dificuldade de se identificar e, principalmente, delimitar a discussão pedagógica se equivale à dificuldade de se identificar ou delimitar os tópicos discursivos em geral. Por sua natureza, a noção de tópico é um pouco vaga e a dinâmica de como ele é desenvolvido pelos interactantes não é completamente compreendida pelos analistas. Um recurso bastante eficiente na demarcação do tópico, mais usado na análise de textos orais, é a identificação de marcadores discursivos produzidos pelos falantes como indícios de mudança tópica. Este recurso nem sempre fica disponível aos estudiosos de textos virtuais que, como as pesquisas mostram, carecem de marcadores. Em compensação, o trabalho do analista pode ser facilitado 
por outra característica: em chats e e-mails, quase sempre, o tópico é anunciado. Isso também ocorre em aulas ${ }^{3}$. (Exemplo 1, linha 2).

\section{Exemplo 1:}

1. adrianna as 20:11:56 em 8-mar-2001:

Qual a dinâmica de hoje?

2. simone as 20:13:45 em 8-mar-2001:

bom, pensamos que seria bom conversarmos um pouco sobre

o que vimos de Vy durante a semana, alguma dúvida ou colocação

que não deu tempo de ser feita ...

(....)

3. simone as 20:18:48 em 8-mar-2001:

vocês acharam algum link referente ao que vimos?

(...)

4. ana e simone as 20: 31:37 em 8-mar-2001:

gente, temos algumas perguntinhas para fazer para você hoje.

Segundo Vy a fala tem uma dupla função que seria $(. . .)^{4}$

(...)

5. ana e simone as 20:35:1 em 8-mar-2001:

vamos às perguntas: 1 - ao falarmos em chat, como este,

exploramos mais a função intelectual da fala

(...)

6. ana e simone as 20:36:46 em 8-mar-2001:

2 - quando interpretamos as intervenções dos outros em um chat, precisamos explorar mais ainda a função intelectual da fala, uma vez que precisamos decodificar a escrita antes de interpretar as mensagens?

(...)

7. Adriana as 20:56:40 em 8-mar-2001:

Ta meio lento, né?

(...)

8. ana e simone as 20:58:18 em 8-mar-2001:

adriana, não estamos sentindo lento o sistema e sim as pessoas que não estão participando ...

9. Adriana as 20:58:35 em 8-mar-2002:

Então lá vai: O que é zona de desenvolvimento proximal?

10. Luciana as 20:58:37 em 8-mar-2001:

Será que na escrita a mensagem é decodificada duas vezes, enquanto na fala uma vez só?

11. Moema as 20:59:2 em 8-mar-2001:

Na escrita, a gente tem que sistematizar as idéias, compô-las ...

12. Adriana as 21:1:9 em 8-mar-2001:

Como assim duas vezes?

(...)

13. ana e simone as $21: 2: 20$ em 8-mar-2001:

zona de desenvolvimento proximal é aquilo que um indivíduo é capaz

${ }^{3}$ Há também a possibilidade do tópico vir anunciado como parte do cabeçalho, como em nossas aulas por e-mail que serão analisadas mais adiante.

4 (...) significa que parte de texto foi omitida. Quando colocado ao final da linha indica que o corte refere-se à contribuição do "falante corrente" (no caso, Ana e Simone); entre linhas, indica a supressão de maiores porções de texto em que estão envolvidas contribuições de outras pessoas. As reticências não são sinais de transcrição, mas parte do texto real. 
de realizar assistido por outro, seja um parceiro, seja um instrutor, seja até mesmo, instrumentos como livros, lições, calculadores, computadores, que são, em última instâncias produtos de outros indivíduos, também representa uma habilidade intelectual do indivíduo ...

(...)

14. moema as 21:3:6 em 8-mar-2001:

Parece-me que vygosty relaciona diretamente (...)

15. ana e simone as 21:3:32 em 8-mar-2001:

... diferentemente da abordagem de Piaget que considerava como

habilidade intelectual humana apenas aquilo que cada indivíduo

era capaz de construir sozinho isolado do ponto de vista da intera

(...)

16. Adriana as 21:3:53 em 8-mar-2002:

Então será que você acha que é todo o contato do indivíduo (...)

(...)

17. ana e simone as 21:3:57 em 8-mar-2001:

sem dúvida Moema é claro que é preciso avançar senão estávamos na

pré-história ...

(...)

18. moema as 21:23:51 em 8-mar-2002:

acho que é quando o indivíduo (...)

(...)

19. Adriana as 21:28:3: em 8-mar-2002:

mas porque chamar de pré-história?

(...)

20. moema as 21:30:47 em 8-mar-2001

podemos relacionar aquele momento, adriana, o surgimento da escrita

na História, com o aprendizado da escrita pelas pessoas. Antes de

saber ler e escrever, eles não sabiam o que perguntar às outras pessoas.

É como se a capacidade de se perceber no mundo fosse reduzida.

21. ana e simone as 21:30:50 em 8-mar-2001:

ah ta...

(...)

22. ana e simone as 21:33:15 em 8-mar-2001:

acho que a humanidade, na realidade ainda é bem bebê ...

(...)

23. ana e simone as 21:34:32 em 8-mar-2001:

então parece que a gente chegou a um acordo ...

(...)

24. moema as 21:35:32 em 8-mar-2001:

eu acho que somos tudo ao mesmo ... a humanidade não vai em

linha reta, nem mesmo o tempo ... isso é coisa de livro de história.

25. ana e simone as 21:36:31 em 8-mar-2001:

gente, precisamos pensar no que vamos fazer a partir deste bate-papo...

Há duas professoras envolvidas, Ana e Simone ${ }^{5}$. A professora Simone explicita o tema (linha 2) e tenta começar a aula (linha 3), sem que tenha sucesso. Minutos mais

${ }^{5}$ Embora o uso das aulas que compõem o corpus do projeto tenha sido autorizado por algum responsável, adotamos a postura de dificultar a identificação dos projetos ou das pessoas como trocando os nomes dos interactantes, já que, em aulas, muitos usuários não usam nicks. Já recebemos permissão por parte de professores, de administradores de escolas ou de responsáveis por projetos e sabemos que o responsável nem sempre tem possibilidade de consultar todos os envolvidos, principalmente os alunos. 
tarde, já na companhia de Ana, faz nova tentativa, desta vez, lançando mão de perguntas, um recurso bastante eficiente na interação em aula (linhas 5 e 6), uma vez que, em situações de ensino, uma pergunta do professor gera uma relevância condicional ainda mais constritiva que em conversações casuais. As iniciativas das professoras não são bem sucedidas e elas reclamam colaboração (linha 8). A aluna Adriana resolve ajudar, lançando uma nova pergunta (linha 9). Simultaneamente, Luciana (linha 10) e Moema (linha 11) também reagem à admoestação das professoras, reportando-se às perguntas feitas vários minutos antes pelas professoras (nas linhas $5 \mathrm{e}$ 6). Adriana (linha 12) faz referência à dúvida de Luciana (na linha 10). Ana e Simone (linha 13 e 15) elegem $^{6}$ a pergunta de Adriana (na linha 9) para responder. As professoras procuram estimular a reação dos interlocutores: respondem à pergunta, mas oferecem uma posição contrária, contrastando Vygotsky e Piaget. Com o artifício, a discussão se instaura.

Pode-se observar que, em aulas, uma discussão dificilmente "brota" de forma natural, pelo contrário, precisa ser perseguida como meta pelos interactantes. Há várias restrições que dificultam o surgimento espontâneo da discussão, sendo as principais, o condicionamento do tópico e dos interlocutores, já que são os alunos - teoricamente os que sabem menos sobre o assunto em pauta - que devem se engajar no debate. Aos professores cabe apenas incitar e monitorar a discussão. Mas, no momento oportuno, é ele que deve dar palavra final, encerrando o tópico.

Isso confere à discussão pedagógica ${ }^{7}$ algumas características peculiares: um tópico é levantado (Ex. 1, linha 9). A iniciativa pode ser do professor ou do aluno, mas é essencial que o tópico seja acadêmico, i.e. relacionado ao que foi previamente estipulado. O tópico é adotado por interlocutores que devem incluir, obrigatoriamente, alunos, tendo em vista que o objetivo da discussão é instruir. O tópico é questionado, surgindo opiniões quase sempre contrárias. Não importa a extensão, um acordo precisa ser atingido no final (linhas 18 a 22). Este acordo deve ser explicitado (linha 23) ou sinalizado pelo professor. Tal como na conversação face a face, o fim da discussão vai sendo negociado pelo reconhecimento do esgotamento do tópico, evidenciado por contribuições mais curtas (linhas 21 a 25), por anáforas resumitivas (Marcuschi, 1992) (linha 24); e por reticências (linhas $17 ; 21 ; 22 ; 24 ; 25$ ) que representam as pausas da conversação face a face.

No Exemplo 1, logo de início, as professoras indicam como esperam que a aula se configure: como uma "conversa" (linha 2). A disposição para discussão é também marcada por professor e alunos através de prefácios a perguntas, como "vamos às perguntas" (linha 4) ou “então lá vai"(linha 9). São comuns expressões de polidez

${ }^{6}$ A julgar pela resposta longa e elaborada das professoras (nas linhas 12 e 14), elas já deveriam estar engajadas na produção da resposta mesmo antes das contribuições de Luciana e Moema terem aparecido na tela.

${ }^{7}$ Mais tecnicamente correto seria dizer que se trata de uma discussão que se insere no domínio discursivo (Marcuschi, 2002) pedagógico. Gracia (1995) sugere que um texto pode ser classificado como texto pedagógico se, observado a partir de suas "funções culturais", tem como principal função a de instruir. No caso, a discussão não se dá por discrepância de opiniões, mas com um objetivo claramente pedagógico. 
positiva do tipo "será que?" (linhas $10 ; 16)$ que maximizam as chances de discussão, dando margem a réplicas. As opiniões também são antecedidas por marcadores de polidez que indicam dúvida como "acho que" (linhas 18, 21, 24) e "parece-me que" (linhas 14, 23), o que também potencializa discussões.

As características mencionadas acima não são vistas como conseqüências naturais do evento de fala (sensu Hymes, 1975) ou do gênero envolvido, mas como estratégias atualizadas pelos interactantes com vistas a objetivos específicos. A ocorrência destas estratégias evidencia que a discussão pedagógica é efetivamente buscada e construída de forma colaborativa.

\subsection{A solicitação de informação em aulas via e-mail}

Não parece estranho que, em aulas, como em qualquer interação em que se supõe que uma parte sabe menos que a outra, haja muita solicitação de informação. Retomando parte da questão central, resta descobrir porque, nas aulas via e-mails, há forte tendência de se tomar as perguntas como demanda de informações, assim coibindo o aparecimento de discussões pedagógicas.

\section{Exemplo 2a:}

De: (aluna)

Para: (professor)

Enviada em: terça-feira, 9 de janeiro de 2000 15:32

Assunto: livro

1 Olá, Gabriel!

2 Como foi de viagem?

3 Eu encontrei afinal o livro que foi citado no meu projeto chamado de "Os bilhões perdidos no lixo" do economista Sabetai Calderoni.

4 Você o conhece? O que acha dele?

Exemplo 2b:

De: (professor)

Para: (aluna)

Enviada em: terça-feira, 10 de janeiro de 2000 15:11

Assunto: re: livro

1 Boa noite.

2. Conheço, o livro pode ser útil para a parte final da monografia.

3. Gabriel.

McElhearn (2000) observou a solicitação de informações em mailing lists. Identificou uma estrutura tripartida, consistindo em solicitação de um "participante 1", resposta de um "participante 2" e agradecimento do "participante 1". O autor analisou outras estruturas mais complexas (por exemplo, quando há pedidos de esclarecimentos complementares ou quando o pedido não é entendido), mas que consistem em variações da estrutura básica descrita por ele. As complexidades podem também se dever a uma maior quantidade de contribuições de pessoas diferentes. 
O autor considera que o terceiro lance (move), o agradecimento, é opcional, devendo seu aparecimento freqüente a regras de etiqueta, já que, em listas, é forte o sentimento de comunidade. O agradecimento também funciona como um marcador de delimitação do evento, indicando que o assunto é considerado como concluído. Já nos e-mails trocados em situação de ensino é comum a ausência de agradecimentos. A supressão de algumas das regras de polidez é característica das interações pedagógicas em geral, já que aí o foco não está nas relações pessoais, mas no conteúdo veiculado. Ademais, professores têm o compromisso institucional de transmitir conhecimentos e não cabe agradecer àqueles que estão apenas desempenhando seus papéis institucionais. Acrescente-se que, diferentemente do que acontece nas listas de McElhearn, é difícil postular que as conversações bilaterais possam provocar sentimento de comunidade, vista enquanto grupo com interesses partilhados.

Nos e-mails entre aluno e professor, a troca de cumprimentos iniciais é freqüente (Ex. 2a, linha 1 - Ex. 2b, linha 1). Já as despedidas são raras. Isso se assemelha ao observado em salas de aulas presenciais onde os alunos geralmente aproveitam o intervalo entre a troca de professores para levantar e conversar. O professor usa o cumprimento inicial como forma de se apropriar do turno e marcar o início da aula, daí a frequiência com que ocorre. A ausência de despedidas é tida como comum em contextos em que há a possibilidade de contínuo reencontro (state of continuing talk), como em escolas. As semelhanças não são coincidência. É razoável supor que os participantes de aulas por e-mails, um gênero em constituição, se apóiem em seu conhecimento de aulas presenciais para interagir, fazendo com que ambas as aulas tenham características comuns.

No Exemplo 2b, o professor responde ao cumprimento da aluna, mas indica um certo grau de afastamento: ao "olá" (Ex. 2a, linha 1) responde com "boa noite" (Ex. 2b, linha 1). Ignora uma pergunta pessoal (Ex. 2a, linha 2) - o que também é comum ocorrer em aulas presenciais - e responde laconicamente à pergunta "acadêmica" da aluna. Uma pergunta como "o que você acha dele?" poderia desencadear uma discussão, mas o professor evita emitir opinião. Tanto a aluna quanto o professor "assinam" seus textos, uma influência clara dos e-mails pessoais que, por sua vez, se assemelham a bilhetes e cartas pessoais.

O exemplo seguinte mostra mais algumas características de aulas via e-mails.

\section{Exemplo 3:}

De: (professor)

Para: (aluno)

Enviada em: terça-feira, 2 de julho de 2002 20:55

Assunto: re: vários

1 > Preciso de novas coordenadas para o desenvolvimento do projeto.

> Você poderia dar mais detalhes sobre o conteúdo do texto?

$>$ Acho que não entendi porque ele diz que a internet

> não é só uma revolução tecnológica mas também social...

2 Tem um texto sobre tecnologia educacional que vai ajudar. (...) Afinal, quando falamos de conversa virtual, não estamos conversando com um computador e sim com um outro ser humano que está do outro lado da rede.

$3>$ O texto também fala sobre um professor que questiona, que orienta, 


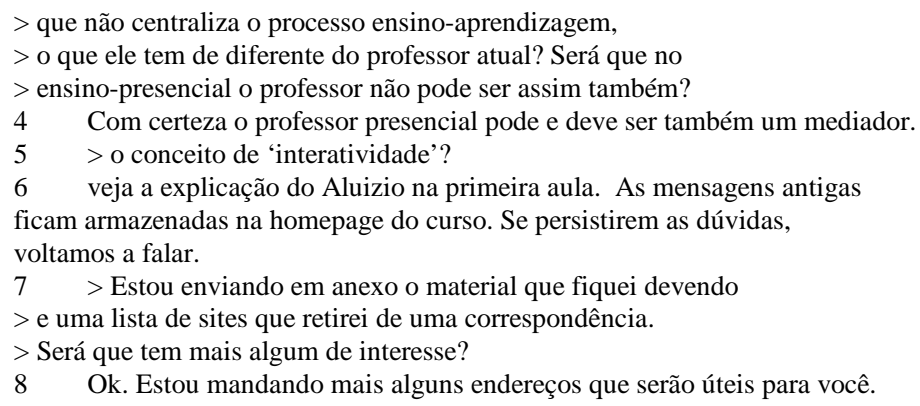

Trata-se da resposta a um texto de aluno que não foi aqui reproduzido. $\mathrm{O}$ professor selecionou, basicamente, as perguntas para citação. Ignorou pedido de desculpas logo no início ("sei que e-mails foram feitos p/ textos curtos, mas tenho muitas dúvidas"). Também não considerou a manifestação de interesse por um tipo de pesquisa (o texto completo do aluno na linha 5 dizia: "outra coisa, também me interessei pelo lado pedagógico depois que o senhor me explicou, mas nesse caso, como ficaria o conceito de interatividade? só consigo pensar no modelo tradicional."). O professor só "colou" só a pergunta, descontextualizando-a. Descartou a manifestação de interesse do aluno em participar concretamente de seu projeto e sua dúvida sobre como proceder numa situação de ensino pelo computador, "não-tradicional". A pergunta perdeu o sentido pretendido (como fazer para otimizar, numa situação de ensino, a interação entre interlocutores virtuais) e foi tratada como uma pergunta técnica sobre o conceito de interatividade.

Observa-se que as contribuições do aluno dão chances a que uma discussão se inicie. Ele usa marcadores como "acho que” (Ex.3, linha 1), "será que?" (linhas 3, 7); discorda de afirmações do texto, fazendo perguntas provocadoras: "o texto fala sobre um professor (virtual) que questiona ... o que ele tem de diferente do professor atual? ... no ensino presencial o professor não pode ser assim também?" (linha 3). O professor é bem impessoal: ao "você poderia" (linha 2) ele responde com "tem um livro", indicando afastamento. Freia a disposição do aluno ao debate (na linha 3) com uma afirmação neutra e lacônica (linha 4).

\section{DISCUSSÃO}

Conforme mencionado anteriormente, uma questão teórica subjacente a este trabalho é se as duas formas de aulas, as aulas chat e as aulas via e-mail, devem ser agrupadas sob um mesmo gênero comunicativo aula ou se devem ser consideradas gêneros diversos. Postulamos que estamos diante de dois gêneros distintos, apoiados na constatação de que é esta a visão dos interactantes, os atores sociais que neles atuam e os constituem. As razões dessa postura ficarão evidenciadas nos comentários que se seguem. Para tentar organizar as observações, vamos nos reportar aos focos sugeridos por Erickson (1997) para o estudo dos gêneros: o propósito comunicativo; a natureza 
da comunidade discursiva; as propriedades das situações recorrentes em que os gêneros são empregados; as regularidades da forma e conteúdo da comunicação e expectativas.

Do ponto de vista do propósito comunicativo, tanto a aula chat quanto a aula via e-mails visam à construção do conhecimento. Elas diferem, no entanto, nas formas como este objetivo global é buscado.

A aula via e-mail é mais centrada no conteúdo. Observa-se a ausência de tópico discursivo a ser colaborativamente construído, mas as questões centram-se em dúvidas pontualizadas dos alunos, tornando a interação fragmentada. As trocas por correio eletrônico são pedaços de aula e não um todo. Em conseqüência, os textos parecem ser concebidos mais como turnos isolados do que como uma conversação. Carecem, assim, de estruturas macro, tanto as típicas de interações em aulas (como as seqüências metatópicas) quanto as de interações casuais (como despedidas - e este é apenas um dos motivos que tornam a interação "menos social" e "mais utilitária"). As iniciativas devem partir dos alunos, cabendo ao professor ficar à disposição e se reportar apenas aos conteúdos por eles levantados.

Nas aulas chat, mais centrada na interação, vê-se uma clara disposição ao diálogo, implícita em expressões como conversar (Ex. 1, linha 2) ou chat / bate papo (Ex.1, linhas 5, 25). Muitas vezes, a intenção de debate é anunciada como uma pré-sequiência, como no exemplo abaixo, gerando expectativas. Embora esse anúncio não seja garantia de que realmente haverá uma discussão, adianta uma disposição de comportamento.

\section{Exemplo 4:}

1. Auxiliadora as 17:7:9 em 6-set-2000:

Conforme combinado em sala de aula, hoje o encontro será virtual! Pesquisem na web documentos que possam ajudar na elaboração do projeto e, a partir das 20:00 hs estaremos na sala de bate-papo para discussões.

Quanto à natureza da comunidade discursiva ${ }^{8}$, há diferenças nas formas como os envolvidos se alinham um em relação ao outro e à própria interação. Em parte, isso advém das orientações diversificadas das aulas, mais centrada na interação ou mais orientada para conteúdo, propiciando envolvimento maior (no caso das aulas chat) ou menor (no caso das aulas por e-mail) entre os participantes.

Vários estudiosos de chats casuais ou de outras CMCs (comunicações mediadas por computador) apontam uma maior igualdade de participação em gêneros virtuais. Aoki (2001) e Kiesler (1991, citado por Aoki, 2001) observam que as pessoas são menos influenciadas por questões de status e outras convenções, evidenciando clara tendência de concentrar a atenção no debate em si. Poster (1990, citado por Aoki, 2001) ratifica, afirmando que, a CMC tende a desestabilizar as hierarquias sociais existentes nas relações entre os interactantes, reorganizando-as de acordo com critérios antes irrelevantes, como a própria interação. As análises de aulas chat ratificam tais afirmações.

${ }^{8}$ Não nos deteremos aqui em discussões sobre o termo comunidade, limitando-nos, apenas, a fazer algumas observações sobre as relações entre os participantes. 
As trocas muitos para muitos (cf. por exemplo, McElhearn, 2000) potencializam a participação. Nelas, todos os usuários enviam mensagens para todos, podendo até mesmo responder mensagens endereçadas a outrem. As aulas chat, como os chats em geral favorecem esse padrão de endereçamento. Harasim (1990) lembra que uma aula com interação assim faz com que "haja uma descentralização do professor e uma recentralização nos alunos". Observando seus dados, diz que o professor começa a aula da forma usual, fazendo uma pergunta à turma. Como muitos alunos respondem rapidamente, o professor não tem oportunidade de fazer avaliações (parte da conhecida estrutura iniciativa - resposta - follow up), dar outras respostas ou introduzir tópicos novos, assim perdendo controle do turno. Aqui novamente, a descentralização confere à aula chat mais características da fala prototípica, se comparada às aulas por e-mail.

São muitas as diferenças em relação às propriedades das situações recorrentes em que as aulas são empregadas. Mas, é fundamental considerar que, na aula chat, a interação se dá de forma síncrona, ou seja, o participante sofre as pressões de ler, seguir as várias linhas conversacionais, refletir sobre conteúdos, fazer correlações, produzir seus textos e enviá-los, tudo de forma rápida e eficiente. No caso dos alunos, faz-se necessário que participem ativamente (já que suas contribuições comprovam sua presença) e que sejam cautelosos com o que dizem (já que são julgados pelo professor). Vê-se que nem todos são igualmente hábeis: na discussão reproduzida no Exemplo 1, além das professoras Ana e Simone, apenas duas alunas participam, embora o grupo conte com mais de trinta alunos ${ }^{9}$.

Essas condições de formulação propiciam o uso de enunciados curtos e objetivos. Também potencializam o uso de termos de endereçamento, usados como elementos coesivos, para facilitar o acompanhamento da interação. Observou-se que, mesmo quando cabeçalhos já evidenciam o destinatário, os usuários repetem o nome de quem produziu a mensagem que está sendo respondida (cf. Ex. 1, linhas 8, 17, 20), assim contornando a dificuldade da falta de seqüenciação dos enunciados. Bays (1998) ainda lembra que este sistema de endereçamento (system of addressivity) compensa a falta do olhar e se equivale à técnica de seleção do próximo falante de Sacks, Schegloff e Jefferson.

Nas aulas via e-mail, assíncronas, os interactantes têm tempo suficiente para compor suas mensagens, podendo estar desconectados da rede. Um recurso muito utilizado é a citação (cola), quer seja para poupar tempo na composição de mensagens quer seja para recuperar o contexto (ou cotexto) em que a resposta se insere (cf. Ex. 3). Esse tipo de citação serve, ainda, como bem lembra McCleary (1996) para marcar o aspecto dual da conversação.

Essas parcas observações (das muitas que poderiam ser feitas) parecem confirmar que - no contexto das aulas estudadas - há forte relação entre as regularidades da

9 Aparentemente, pode-se argumentar que a tendência à discussão nas aulas chat reflete o número de participantes. É claro que interações multilaterais propiciam o debate, mas esse não é o aspecto determinante aqui, já que apenas duas alunas se envolvem na discussão. Por outro lado, pode haver discussões em interações bilaterais. É também preciso considerar o contexto situacional. Uma sala de aula presencial envolve muitos participantes, mas, nela a conversação é bipartida (professor vs. alunos). 
forma e conteúdo da comunicação e os gêneros envolvidos. Comparando-se as aulas chat e aulas por e-mail, percebe-se que há diferenças substantivas nas expectativas dos interactantes em relação à atividade da qual tomam parte, o que leva, por exemplo, a leituras diferenciadas a respeito de perguntas, que se observadas fora do contexto dos gêneros textuais ${ }^{10}$, parecem semelhantes. Como ficou evidente, por suas características, a aula chat se assemelha mais à fala prototípica que a aula por e-mail. Postulou-se que as estruturas não ocorrem de forma randômica no contexto dos gêneros focalizados, o que equivale a dizer que tais estruturas não são vistas como produtos, mas como estratégias atualizadas pelos interactantes (que, é claro, têm objetivos e precisam se submeter a certas condições). Centrada em enunciados particulares, a perspectiva do trabalho insere o estudo da língua nas escolhas individuais de produção e compreensão de textos, propondo-se a tentar explicar aspectos da variação e escolha lingüísticas através da observação detalhada sobre como os participantes de uma interação interpretam o contexto situacional em que se comunicam.

\section{$\overline{\text { REFERÊNCIAS BIBLIOGRÁFICAS }}$}

ADAM, Jean-Michel. (1990). Élements de Linguistique Textuelle. Theorie et Pratique de l'Analyse Textuelle. Liège: Mardaga.

AOKI, Kumiko. (2001). Synchornous Multi-User Textual Communication in International TeleCollaboration. http://www.firstmonday.dk/issues/issue2_murphy.

BAYS, Hillary. (1998). Échanges Conversationnels Sur Internet: une analyse sociolinguistique d'un nouveau mode de communication. Mimeo.

BRONCKART, Jean-Paul. (1999). Atividade de Linguagem, Textos e Discursos. Por um Interacionismo Sócio-discursivo. São Paulo: EDUC.

ERICKSON, Thomas. (1997). Social interaction on the Net: virtual comunicty as participatory genre. http://org/personal/Tom Erickson/vc_as_genre.html.

GRACIA, Jorge. (1995). A Theory of Textuality. The logic and epistemology. New York: State University.

HARASIM, Linda. (1990). Online Education: an Environment for Collaboration and Intellectual Amplification. In Linda Harasim (ed.), Online Education: perspectives on a New Environment. New York: Praeger Publishers, pp. 39-64.

HYMES, Dell. (1986). (3 ${ }^{\text {rd }}$ ed.) Models of Interaction of Language and Social Life. In Dell Hymes \& John Gumperz, Directions in Sociolinguistics, pp. 35-71.

MARCUSCHI, Luiz Antônio. (1992). A Repetição na Língua Falada: Formas e Funções. Recife, UFPE. Tese de Titular para Lingüística, mimeo. . (2002). Gêneros Textuais e Ensino de Língua. Mimeo.

${ }^{10}$ Acrescente-se que as mais conhecidas tipologias de perguntas foram elaboradas a partir do ponto de vista das intenções do autor e não levando em conta sua recepção. 
MCCLEARY, Leland Emerson. (1996). Aspectos de uma Modalidade de Discurso Mediado por Computador. Tese de DO, FFLCH, USP.

McELHEARN, Kirk. (2000). Writing Conversation: Analysis of Speech Events in E-mail Mailing Lists. Revue Française de Linguistique Appliquée. Vol. V-1, June 2000. 